\title{
IMPROVEMENT OF DYNAMIC PERFORMANCE OF DFIG BASED WIND TURBINE
}

\author{
${ }^{1}$ Dr. S. Venkateshwarlul, ${ }^{2}$ P. Samyuktha, 3 Dr. K. Naga Sujatha \\ ${ }^{1}$ Prof \& HOD of EEE, CVR College of Engineering, ${ }^{2}$ Research Scholar, JNTUH, ${ }^{3}$ Prof. of EEE and \\ Coordinator, Academic \& Planning, JNTUH \\ Email:svip123@gmail.com, samyuktha.penta@gmail.com, knsjntuh@gmail.com
}

Received: 10 ${ }^{\text {th }}$ Feb 2018, Accepted: 20 $^{\text {th }}$ March 2018, Published: 30 $^{\text {th }}$ April 2018

\begin{abstract}
The negative effect of green house impact, the option and sustainable power source alternatives have gotten huge consideration on worldwide scale. Wind energy has turned out to be one of most adequate arrangement among the distinctive sustainable power source assets as a result of the use of power electronic based controllers that permits the wind energy conversion system (WECS) to create quality electric power independent of variable wind profile. The nonstop stream of value power from WECS to grid is guaranteed for more extensive scope of wind speed. Doubly encouraged enlistment generator (DFIG) utilized as a part of WECS having power electronic converter which requires little portion of power in contrast with the aggregate age limit. Wind power age systems in view of a doubly bolstered acceptance generator (DFIG) have procured expanding fame everywhere throughout the world because of the benefits of littler converter rating, autonomous direction of dynamic and responsive powers, bring down converter cost and power misfortunes contrasted and the settled speed enlistment generators or synchronous generators with full-sized converters. The appropriate Maximum power point following (MPPT) method has likewise been proposed to tackle most extreme accessible power for a given wind velocity to guarantee the nonstop power spill out of WECS to the power grid.
\end{abstract}

Keywords: wind energy conversion system, Wind Turbines, DFIG Based Wind Turbines

\section{Introduction}

The control technique of a DFIG system under a perfect power grid has been very much explored to fulfill the prerequisites of wind energy conversion and grid code. In addition, the DFIG electromagnetic torque throb caused by a nonperfect grid voltage would likewise be hurtful to mechanical units, for example, the gearbox and rotor bearing. It is basic to enhance the DFIG control technique to dispose of these inconvenient impacts. Up to now, the control procedure of DFIG under unequal grid voltage has been explored to dispense with the hurtful impact of the grid voltage negative grouping, that is, the lopsided stator current, quick stator active $\&$ reactive power pulsations, and electromagnetic torque throb. Then again, when grid voltage contortion happens, have exhibited a numerical demonstrating and control system for DFIG under agreeably misshaped grid voltage conditions, in which the option control targets were proposed to expel pleasingly mutilated stator current, limit stator active and reactive power pulsations, or smother electromagnetic torque throb. These investigations were executed in light of the grid voltage negative and consonant grouping decay. At that point the unavoidable stage postponement and time delay because of the work of the indent channels and lowpass channels would be presented as a result, and the decay precision and system dynamic reaction would likewise break down. Expanded measure of power created from WECS is one of the approaches to achieve the objective of bringing down discharges of nursery gasses from energy generation. Introduced wind turbines and wind power plants have expanded both in size and number as of late fundamentally.

\section{POWER CHARACTERISTICS OF WIND TURBINE}

Wind turbine is a non-linear system whose yield relies upon different parameters, for example, wind velocity, measurements of the wind turbine and tip speed proportion. The power extricated by a wind turbine is

$$
P_{\text {avail }}=\frac{1}{2} \rho A v^{3}
$$

where $\mathrm{v}$ is the wind speed, $\rho$ is the air thickness, A is the range cleared by the cutting edges and $\mathrm{Cp}$ is the wind power coefficient (signifies power extraction proficiency which is a component of $\beta$ and $\lambda, \beta$ being the pitch edge and $\lambda$ being the tip speed proportion - TSR given by $\mathrm{R} \Omega / \mathrm{v}$ where $\mathrm{R}$ is turbine span, $\Omega$ is turbine shaft speed). Consequently, power caught by the wind turbine is intensely reliant upon TSR when $\beta$ is unaltered. The power conversion productivity has an all around decided most extreme $C_{\text {pmax }}$ for a particular tip speed proportion $\lambda$. The ideal control of active power in a variable-speed settled pitch WECS can along these lines be effortlessly accomplished, if $\lambda$ is controlled for achieving the $C_{\text {pmax }}$ comparing to a given wind velocity

$$
\begin{gathered}
p_{w t}=0.5 \hat{\mathrm{C}}_{p}(\lambda, \beta) \rho \pi R^{2} V^{3} \\
T_{w t}=0.5 \hat{\mathrm{C}}_{p}(\lambda) / \lambda_{3} \rho \pi R^{5} V \Omega^{3}
\end{gathered}
$$

Along these lines the torque created by the turbine is processed as $T_{w t}=p_{w t} / \Omega$.Hence the torque 
delivered by the turbine is relative to $\Omega 2$ and power is corresponding to $\Omega 3$ as appeared in fig4. Thus, by the above conditions it can be seen that for a specific TSR, the power removed by the turbine is most extreme for a given wind velocity ( $\omega$ speak to speed)

\section{WIND ENERGY CONVERSION SYSTEM (WECS)}

Green house gas diminishment has been one of the pivotal and inescapable worldwide difficulties. The issue has come into concentrate particularly over the most recent two decades as confirmations on a dangerous atmospheric deviation have been accounted for. This has attracted expanding consideration regarding sustainable power sources including wind energy. WECS has yearly establishment development rate of $31.7 \%$ of every 2009 with its development rate is consistently expanding throughout the previous couple of years. The wind energy is presently one of the quickest developing and attractive sustainable power sources. The expanding value aggressiveness of wind energy against other customary petroleum derivative energy sources, for example, coal and flammable gas is another positive. WECS comprises of three noteworthy viewpoints; aerodynamic, mechanical and electrical. The electrical part of WECS can additionally be separated into three fundamental segments, which are wind turbine generators (WTGs), power electronic converters (PECs) and the utility grid. In equipped drive wind turbines, one traditional arrangement is a numerous stage adapt with a fast generator; the other one is the multi grid idea which has a solitary stage outfit and a low-speed generator. In this segment, as indicated by contemporary wind turbine ideas, the fundamental setups and qualities of various wind generator systems are depicted. All wind turbines introduced up to now utilize both of the accompanying systems: (a) settled speed enlistment generator (squirrel confine acceptance generator); (b) doubly encouraged enlistment generator; (c) coordinate drive synchronous generator as appeared infig1

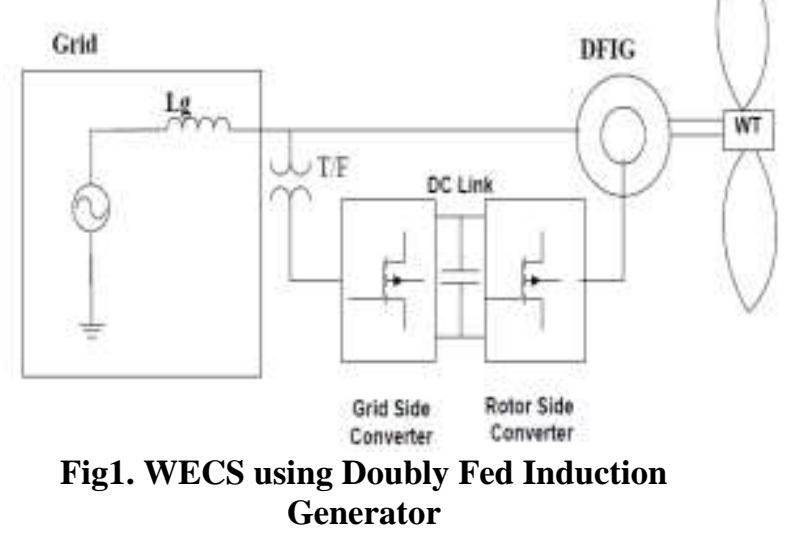

\section{A. Wind Turbine Generators}

With the thought to its operation speed and the extent of the related converters, WTGs can be arranged into three classes in particular:

- $\quad$ Fixed Speed Wind Turbine (FSWT)

- Variable Speed Wind Turbine (VSWT) with partial scale frequency converter (PSFC)

- Variable Speed Wind Turbine (VSWT) with full scale frequency converter (FSFC)

FSWT including Squirrel-Cage Induction Generator (SCIG), drove the market until 2003. The DoublyFed Induction Generator (DFIG), which is the fundamental idea of VSWT with PSFC, overwhelmed FSWT and has been driving WTG idea. It about has $85 \%$ of the piece of the overall industry.

\section{B.Variable Speed Wind Turbines}

The wind turbines might be of flat pivot or vertical hub sorts. These turbines can be settled speed and variable speed wind turbines. The settled speed wind turbines pivot at just about a steady speed, which is controlled by the apparatus proportion, the grid recurrence, and the quantity of shafts of the generator. The greatest conversion proficiency can be accomplished just at a given wind speed, and the system productivity corrupts at other wind speeds. This sort of turbine likewise requires a durable mechanical outline to assimilate high mechanical anxieties. Then again, factor speed wind turbines can accomplish most extreme energy conversion productivity over an extensive variety of wind speeds. The turbine can constantly change its rotational speed as indicated by the wind speed. To influence the turbine to speed movable, the wind turbine generator is ordinarily associated with the utility grid through a power converter system. The converter system empowers the control of the speed of the generator that is mechanically coupled to the rotor (cutting edges) of the wind turbine. The principle points of interest of the variable-speed turbine incorporate expanded wind energy yield, enhanced power quality, and lessened mechanical anxiety. The fundamental disadvantages are the expanded assembling expense and power misfortunes because of the utilization of power converters. the smoother operation gave by the controlled generator diminishes mechanical weight on the turbine, the drive prepare and the supporting structure. This has empowered producers to create bigger wind turbines that are more financially savvy. Because of the above reasons, variable speed turbines command the present market. 


\section{MAXIMUM POWER POINT TRACKING (MPPT)}

The fundamental point of MPPT controller is to expand the generator proficiency without the requirement for a low speed or fast shaft encoder, wiping out worry about sensor unwavering quality. The reason for the MPPT is to guarantee that the most extreme accessible energy from wind is removed for a specific mix of wind turbine, generator and the power electronic converter of the WECS. The noteworthy motivation behind the MPPT is to guarantee the tip speed proportion of the wind turbine as close as conceivable to ideal tip speed proportion. As the operation conditions are wind profile subordinate in this manner all the MPPT strategies recognized are not reasonable for all sort of wind generators. MPPT systems like slope climb method (HCS), tip speed proportion (TSR), anemometer strategy, MPPT calculations by changing the speed reference and mapping power procedure in which the maps/bends are utilized to discover the ideal purpose of operation which functions admirably in the smooth wind conditions. The fundamental and imperative preferred standpoint of the MPPT is to work the WECS at variable wind profile with ideal yield. This contributes altogether in the improvement and development of WECS to build its investment in the net worldwide power age.

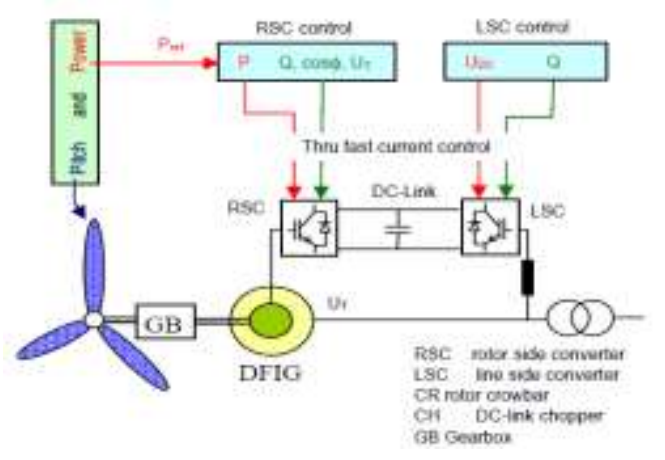

Fig2. Structure of the DFIG based wind turbine

The rotor of the DFIG is outfitted with three stage Windings, which are provided by means of the rotor side slip rings by a voltage source converter (VSC) of variable Recurrence and size as appeared in fig2. Speed changeability is guaranteed by the bidirectional exchange of slip power by means of the recurrence converter. The control of the DFIG wind turbine typifies three Parts.

- Speed control by controlling the electrical power reference provided to the converter as well as by the pitch angle.

- Rotor side converter (RSC) control directed at the control of active and reactive power on the stator side.
- Line side converter (LSC) control that keeps the DC link voltage constant and provides the additional opportunity to supply reactive power into the grid.

\section{DOUBLY FED INDUCTION GENERATORS (DFIG)}

The doubly encouraged enlistment generators (DFIG) are wound rotor acceptance generator. The DFIG depends on the idea, which compares to a variable speed wind turbine design with an injury rotor enlistment generator (WRIG) and an incomplete scale power electronic converter on the rotor circuit idea bolsters a wide speed go operation, contingent upon the span of the recurrence converter. In a regular usage of a grid-associated DFIG, consecutive converters are utilized to interface the DFIG rotor to the utility. The rotor side converter controls the charging and torque rotor currents. The grid side converter controls the voltage in the dc transport of the consecutive converters The wind turbine transmits mechanical power to the DFIG through a drive prepare as per ostensible turbine speed, number of generator shaft matches and organize recurrence. According to the wind profile the working states of the WECS changes between the sub-synchronous to super synchronous range. The parameter recording unit measures the prompt estimation of rotor speed and the relating signals are nourished to the control unit playing out the greatest power point following operation. On the premise of the signs from the parameter recording unit and the MPPT control unit the relating signals are encouraged to the network converter unit as appeared in Fig.3. The slip esteem changes in like manner. The slip power streams from and to the rotor circuit through the Rotor Side Converter for the super and sub-synchronous operation methods of operations separately.

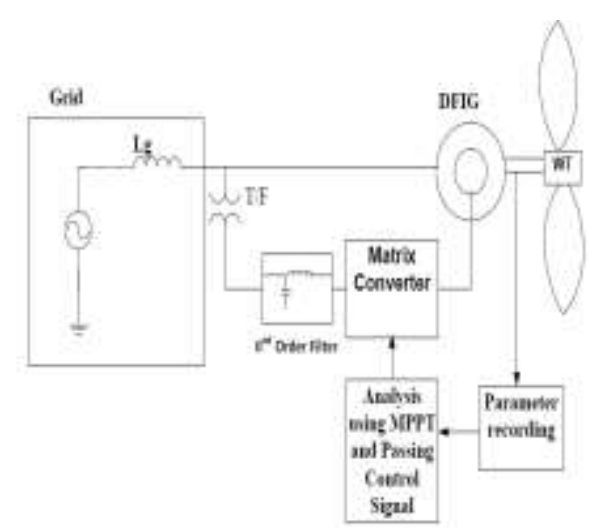

Fig3. Proposed DFIG-based WECS Control

The Matrix Converter (MC) gives bidirectional power flow, sinusoidal info/yield currents, and controllable information power factor. When contrasted with consecutive converters, the MC has some significant focal points. For example, because 
of the nonattendance of electrolytic capacitors, the MC can possibly be powerful and solid. In the MC input side, a moment arrange LC power filter is utilized to enhance the current waveform and decrease the info voltage mutilation as appeared in fig3. wind energy conversion system utilizing DFIG for different generator-converters topologies. The cost of the general system increments as the intricacy of the power electronic converter increments. The multifaceted design of the controller configuration likewise influences cost; for instance, the utilization of MPPT systems. There are different points of interest of DFIG announced as its controllability of both active and reactive power is better. The extensive rotor idleness smoothes the varieties of wind speed and therefore it has less vacillations in yield power. The most vital favorable position of DFIG is its capacity to get ride through blame by its uninterruptible operation. DFIGs associate with grid with choosing a decent control; it has uninterruptible operation and can effectively ride through grid flaws. The uninterruptible operation can be accomplished by appropriately organizing the operation and control of the converters and utilizing dynamic reactive pay.

\section{TOPOLOGIES OF DFIG}

The Doubly-fed induction generators are mostly of the following categories.

- $\quad$ Slip Ring Induction Generator.

- Brushless Doubly Fed Induction Generator.

\section{Slip Ring Induction Generator}

In this topology is stator circuit is specifically associated with the grid while the rotor circuit is associated with grid by means of slip rings and three stage converters. The DFIG is currently the system of decision for multi-MW wind turbines. The DFIG system thusly works in both sub-and supersynchronous modes with a rotor speed extend around the synchronous speed. The DFIG offers satisfactory execution and is adequate for the speed extend required to misuse run of the mill wind assets. An AC-DC-AC converter is incorporated into the enlistment generator rotor circuit. Since the rotor speed of the DFIG is customization, by utilizing the most extreme power point following (MPPT) plans which can be actualized to collect the greatest accessible power from the wind turbine. While working at the greatest power point (MPP) on the turbine power-speed bends, the generator's mechanical power from the pole ,Pm ${ }^{\text {ee }}$ is relative to the $3 \mathrm{D}$ shape of the rotor speed , $\omega \mathrm{r}^{\mathrm{re}}$. Dynamically, the DFIG may work at $30 \%$ over the synchronous speed. As a result, the power converters in the rotor circuit ought to be intended to deal with around $30 \%$ of the evaluated stator power.
Brushless Doubly Fed Induction Generator. The most significant features of the Brushless DFIG are

a) no brushes are required,

b) it utilizes a fractionally rated converter,

c) it shows greater compatibility with grid codes than the conventional DFIG, thereby providing substantial economic benefits.

The Brushless DFIG is particularly attractive as an alternative replacement for doubly-fed slip-ring induction generators (DFIGs) in wind power plants, as brushless operation reduces the maintenance requirements and increases reliability. The brushless doubly-fed machine can also be used as a motor in variable speed drive applications, making it the ideal choice in pumping, as well as many other applications.

\section{Results and Discussion}

Simulation studies are performed with the following parameters.

\section{Circuit Simulation Parameters}

Stator Resistance $=30.7 \mathrm{mohm}$

Rotor resistance $=40.3 \mathrm{mohm}$

Stator Leakage Resistance $=0.49 \mathrm{mH}$

Rotor Leakage Resistance $=0.59 \mathrm{mH}$

Power Capture Coefficient between 0.4829 and 0.4059

The proposed DFIG based WECS using matrix converter topology described is simulated using MATLAB at variable wind velocities to operate the system. The various parameters like stator current, rotor current as shown in fig6, real power and reactive power were analyzed.

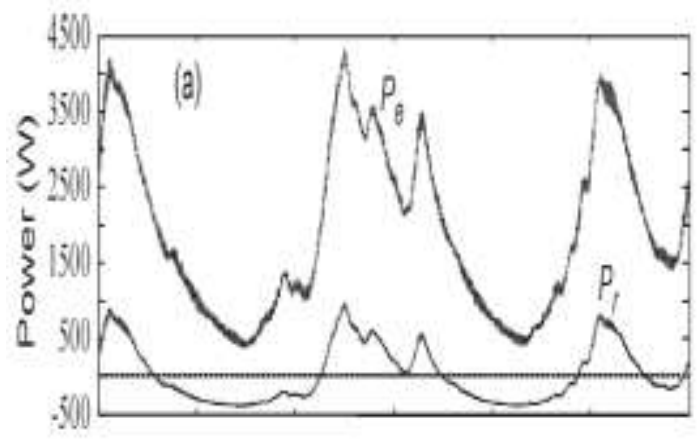

Fig4.DFIG output power $\boldsymbol{P}_{\boldsymbol{m}}$ and rotor power $\boldsymbol{P}_{\boldsymbol{r}}$. Electrical Output Power is extracted is Maximum at power coefficient 0.4829 as shown in fig4. 


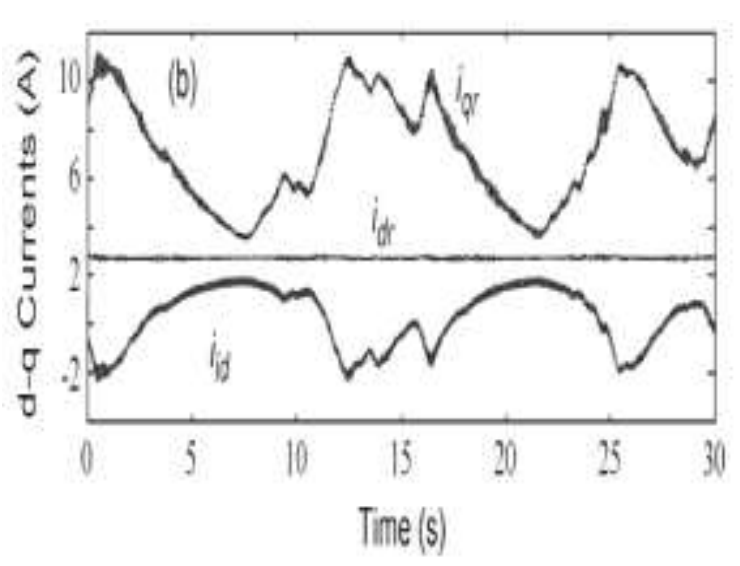

Fig5. DFIG rotor currents and MC input current.

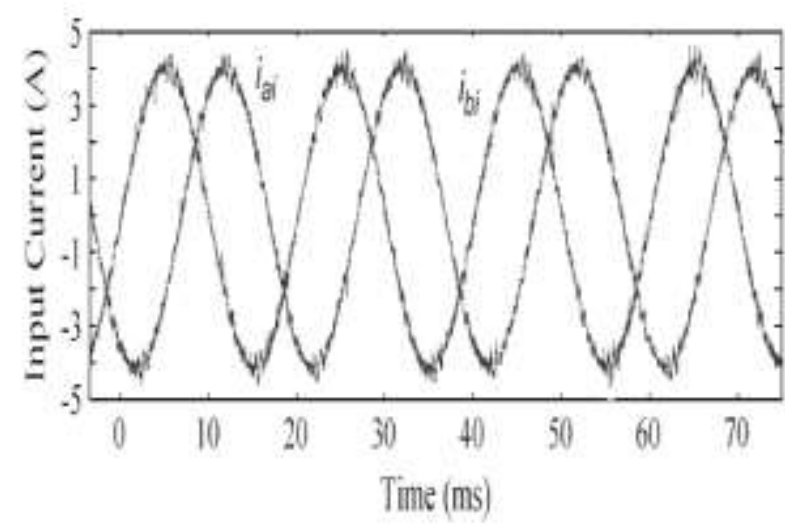

Fig6.MC input current for operation with a cutoff frequency of $50 \mathrm{~Hz}$ in the rotating filter.

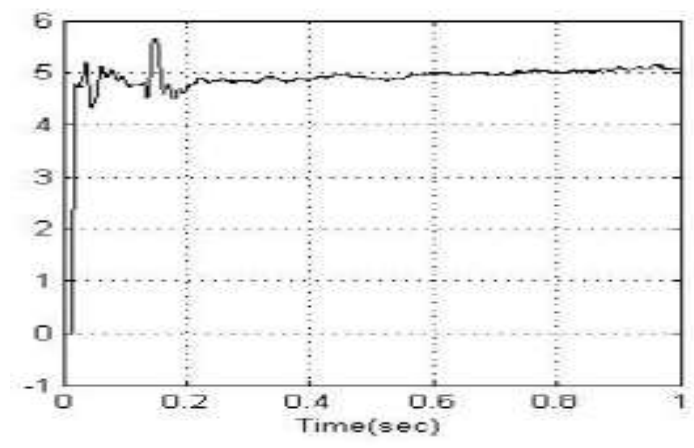

Fig 7. Real Power for proposed WECS

The real power obtained from the proposed WECS is shown in Fig.7. It is observed that after $0.2 \mathrm{sec}$ the real power is stable and quality power is generated at variable speed wind profile as shown in fig8.

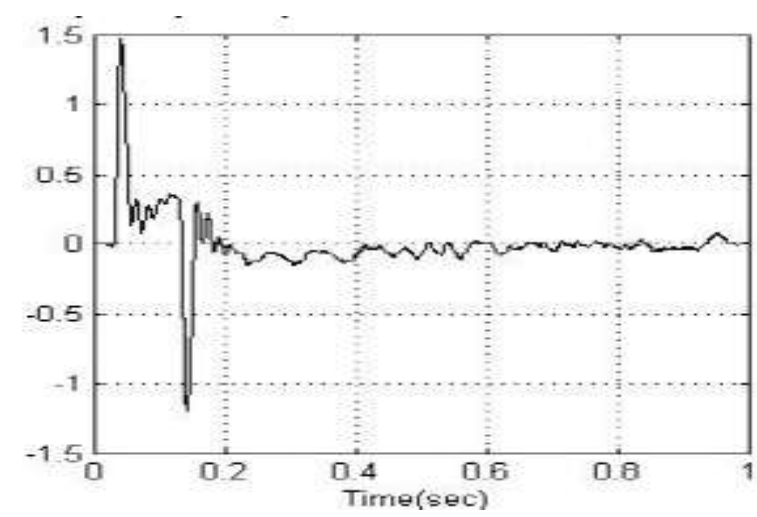

Fig 8. The reactive power characteristic

\section{Conclusion}

This paper introduces a procedure for DFIG under lopsided and mutilated grid in view of DFIG based wind turbine systems are intensely worried amid grid flaws. It is inferred that the power-electronic innovation assumes an imperative part in the mix of sustainable power sources into the power grid under factor wind situation. The notoriety of DFIG systems are because of its upper hands over different sorts of generators and henceforth are all the more generally being utilized as a part of vast power grids keeping in mind the end goal to add power to the grid. The control conspire adaptively evaluates the wind power catch coefficient utilizing ongoing wind and rotor speed esteems. In the paper it is exhibited that the reasonable MPPT strategy for the wind energy conversion system including a MC guarantees the most extreme conceivable quality power age at variable wind profile. The reenactment comes about demonstrate that the execution of the grid associated WECS is better at variable wind profile utilizing network converter. This control system was created in a MATLAB/Simulink condition

\section{Rererences}

1. MM. Aten, G. Towers, C. Whitley, P. Wheeler, J. Clare, and K. Bradley, "Reliability comparison of matrix and other converter topologies," IEEE Trans. Aerosp. Electron. Syst., vola. 42, no. 3, pp. 867-875, Jul. 2006.

2. RR. Peña, R. Cárdenas, J. Proboste, G. Asher, and J. Clare, "Sensorless control of doubly-fed induction generators using a rotor-currentbased MRAS observer," IEEE Trans. Ind. Electron., vola. 55, no. 1, pp. 330-339, Jan. 2008.

3. MMeng, W., Yang, Q., Ying, Y., Sun, Y., Yang, Z. , and Sun, Y. , -Adaptive power capture control of variable-speed wind energy conversion systems with guaranteed transient and steady-state performance,\|l IEEE Trans. Energy Convers., vola. 28, no. 3, pp. 716-725, 2013.

4. PPatsios, C., Chaniotis, A., and Kladas, A., -A Hybrid Maximum Power Point Tracking 
System For Grid-Connected Variable Speed WindGenerators -, IEEE Power Electronics Specialists Conference, 2008. PESC 2008, pp. 1749 - 1754, 2008.

5. FFariba Fateh, Student Member, IEEE, Warren N. White, and Don Gruenbacher, Member, IEEE, "A Maximum Power Tracking Technique for Grid-Connected DFIG-Based Wind Turbines", IEEE Journal of Emerging and Selected Topics in Power Electronics.

6. WW. E. Leithead and B. Connor, "Control of variable speed wind turbines: Design task," Int. J. Control, vola. 73, no. 13, pp. 1189-1212, 2000.

7. ZZhaohong Bie, Xin Zou, Zijing Wang, and Xifan Wang, - Studies on Models and Algorithms of The Power System Probabilistic Production Simulation Integrated With Wind Farmll IEEE Power \& Energy Society General Meeting,2009. PES' 09.

8. EE. Iyasere, M. Salah, D. Dawson, J. Wagner, and E. Tatlicioglu, "Optimum seeking-based non-linear controller to maximize energy capture in a variable speed wind turbine," IET Control Theory \& Appl., vola. 6, no. 4, pp. 526532, 2012. 